Journal of Law \& Social Studies (JLSS)

Volume 1, Issue 1, pp 1-12

www.advancelrf.org

\title{
Exploring Turnover Reason: A study of BPO Industry of Pakistan
}

\author{
Zahid Juma \\ Phd Scholar, NUST Business School, \\ National University of Science \& Technology, Islamabad \\ zahid.phd18@nbs.nust.edu.pk \\ Muhammad Waqar Arshad \\ Phd Scholar, NUST Business School, \\ National University of Science \& Technology, Islamabad \\ waqar.phd18@nbs.nust.edu.pk
}

\begin{abstract}
This study explores the determinants of voluntary and involuntary turnover intention of the BPO industry of Pakistan taking sample of one of leading BPO situated in Pakistan. Our study is based on two main themes; voluntary and involuntary turnover. For voluntary turnover we have explored one main category called 'resignation' but for involuntary turnover two main categories we have identified from the data and these are 'termination' and 'separation'. Some of the determinants that we have explored for each theme are common in turnover intention literature like career advancement and bad performance but some are new like "no call no show" which means if an employee leaves the organization without any notice and didn't appear. Over all the antecedents of turnover that we have found are Cost Cutting, Insubordination, Malpractice, Poor Performance, Violating Company Policies \& Procedures, Negative behavior, no call no Show, Career Advancement, could not manage his studies \& work, Grievance with the management, Medical Issues, Moving to new city, Personal Issues, Remuneration, Study Completion, Work life balance. Moreover, this study enhanced the existing theoretical framework of the Hanqin Qui et al (2014). If we see their framework, they have just showed up the turnover intention in one layer in hotel industry of the China, but in our study we have extended it in two layers, called categories of turnover and then subcategory of each category. But at the same time this study has some limitations. Data of turnover intention is of one BPO situated in Pakistan thus we cannot generalize the result of this study at all BPO industry employees. Future research can be done taking the data more than one BPO organization and conducting interviews of employees.
\end{abstract}

Keywords: Turnover intention, BPO industry, involuntary turnover, Voluntary turnover

\section{Introduction:}

Business process outsourcing industry has benefitted the developing countries like Pakistan, Philippine and India by giving thousands of jobs and also helped the developed countries organization to reduce their cost. As (Shah and Sharma 2007) claimed that business process outsourcing is the one of the most obvious choices of the developed country organizations to reduce their cost and increase their shareholder value. This industry perform the less important business processes of the big firms which is outsourced by the big firm (also including fortune 500) to reduce their cost and to focus on the core business and this strategy is prevailing in leading organization now a day and most common form of business outsourced is of call center services (Malhotra, Gautam, Programmes, \& Park, 2016). But like every organization setup business process outsourcing industry also faces the issue of employee turnover and the ratio of turnover is high due to many reasons that we will identity in this study. Employees turnover is a ratio of replacing new employees with old one and its reasons can be mainly divided into two main category called involuntary and voluntary turnover. Involuntary turnover include the employees get laid off due to cost cutting and being terminated due to policy violation whereas, voluntary turnover includes when employee leave the organization at their own decision (Dess and Shaw, 2001). The first and foremost priority of the organization is to make the good environment that employees want to remain with and outsider also wants to get hired in that organization and after that the retention of the employees is the main concern but high turnover of employees is more challenging issue in 
every type of organization and specifically in business process outsourcing center (Chaturvedi \& Sangwan, 2016). In context of human resource, if the employer of the company has high turnover in comparison to its competitor, it means on average the tenure of that organization is shorter than the other competitor which is harmful (Purohit, 2016). And more specifically, the role of knowledge worker is very important in organization as they have key responsibility in making company successful ( $\mathrm{Li}, \mathrm{Xu}$, Wang, Chen, \& Sun, 2018). Every type of organization faces this challenge in contemporary dynamic era of competition and specifically in Pakistan business process outsourcing industry is in growing phase that is why this study is mainly focus on the leading business process outsourcing (BPO herein after) company situated in Pakistan and will try to find out the main reason of voluntary and involuntary turnover in that particular company. As BPO industry is in growing phase and this situation put the existing BPO organization in fierce competition to retain their employees so it is important to find out the main reasons of turnover so that it may helpful for the organizations to retain their employees.

This study will find out the main reasons of voluntary and involuntary turnover of one of the leading organization situated in Pakistan. Further this study will be structured as follows, in section two comprehensive literature review in section three methodology and data analysis, in section four discussion, in section five proposed framework followed by conclusion in section six.

\section{Literature review:}

As this study is based on qualitative analysis of the turnover intentions, but in literature most of studies on turnover are based on quantitative analysis however, result of these studies also relevant to our study. In reviewing literature, starting from the study (Chakrabarti \& Guha, 2016) where they have stipulated an in-depth exploration of qualitative theme of contradicting accounts of reasons of employee's quit from their job as well as some managerial strategies to prevent employees from turnover in Indian business process outsourcing. They have found that turnover in BPO industry in India is not linear process as highlighted in most model of employee's turnover as people are more attached to place and people rather than the organizations. And the most important finding of the study is the identification of intergenerational difference between the employees who belongs to $\mathrm{Y}$ generation and managers who belongs to generation $X$ and ineffectiveness of adopted HR practices lead to push strategy of human resource system. In the same spirit of Y generation study,(Brown, Thomas, \& Bosselman, 2015) have conducted study on Y generation taking the population of US four year hospitality program. As the BPO industry contain the employees having age of Y generation, so we can say that the result of this study can be apply to BPO industry. In this study they have concluded that generation Y employees mostly desire more challenging jobs but at the same time they think of long term career. (Malhotra et al., 2016) also discussed the same challenge of Indian BPO's by reviewing the different research paper on this issue, where high employee's turnover cause huge performance and monetary setbacks to the organizations. Gupta, V. (2013) stated that the main reason for high turnover in BPO industry is the odd timing of office as night shift is completely contradicting with the usual life and it disturbs the work life balance. Thamizharasi \& Rani, (2014) found that longer working hours and doing multiple jobs are the main cause of job dissatisfaction which lead to turnover. Sivarethinamohan \& Aranganathan, (2013); Bharathi \& Paramashivaiah, (2015) stated that the main reasons for high attrition is the low career growth as the experience of BPO is not acceptable in the market as other organization experience and also the job security, lack of skill variety lead to attrition. Chaturvedi \& Sangwan, (2016) also consider human resource of IT enable services as a vital component and highlighted the challenge of attrition. They have stated that the attrition of employees can be undone if we satisfy motivate our employees and also it will positively impact the companies by enhancing employee's performance and quality of work.

Apart from the BPO industry there are many other field of business where researcher have conducted study and suggested different areas to overcome. Rahman, (2017)worked on banking industry of Bangladesh and claimed that even having excellent benefit to the employees, the dilemma of employee attrition happens due to physical stress, lack of proper training, and transfer of jobs. Li et al., (2018) used the term of "knowledge worker" who are highly educated resources of the organization use the information and knowledge to make the organization successful. However, they have analyzed that in chines firms there is high voluntary turnover of these knowledge worker and conducted study to find out the reasons of this high voluntary turnover. They have used the five factor model and Chinese personality assessment inventory to assess the reason of knowledge worker turnover and concluded that Chinese company should give attention to female employees specially who put high value on their family, secondly those employees who are 
from non-research and development departments and finally those employees who are more willing to new experience. In the same line, (Alam, 2015) conducted study on pharmaceutical sector Khulna city Bangladesh and find out the reasons of medical promotion officer's turnover and their job satisfaction. By conducting survey, they have concluded that due to the job insecurity, work load, less social life, no fringe benefits and low social status are the main causes of job dissatisfaction. Further they have identified that turnover rate can be restrained using force field analysis model. Hayward, Bungay, Wolff, \& Macdonald, (2016) conducted study to check the reasons of turnover of experienced nurses by examining the personal and environmental factors that may influence them to leave. The motivation behind this study is to reduce recruitment and orientation cost and to increase quality of patient cares and they have operationalized the study using the qualitative approach of the research conducting interviews if 12 registered nurses having average experience age more than 16 years. The result suggested that higher patient acuity, workload and less effective working relationship between nurses and physicians, ineffective leadership are some important insights that leads the nurses to think of turnover lastly they have concluded that effective and supportive leadership behavior and collaborative practices can reduce the nurse's turnover. In same line (Malik, Sattar, Shahzad, \& Faiz, 2017) have conducted study on public sector nurses to check the direct impact of bullying on nurses turnover as well as the mediating role of bullying on turnover intention via job stress. Also they have check the moderating role of political skill in an association between job stress and bullying The novelty bring in this study is the use of mix method and they have validated the quantitative result by qualitative method through interviews. The result suggests that personal bullying has direct as well as mediating effect on turnover intention of the nurses via job stress but the political skill can weaken the impact of bullying on job stress. Qiu, Haobin Ye, Hung, \& York, (2015) conducted study on hotel employees of the Shenzhen, China taking three focus group interviews of with thirteen supervisor employees. They have operationalized the study by generating themes that explains the turnover intention of hotel employees which includes work-life balance, group cohesion of worker, advancement opportunity, leadership role and finally the remuneration. Additionally, they have suggested another theme which is 'community fit' which explain the turnover intentions, and this theme say if the environment of the city is good and they think that they can pursue their career in city they will tend to stay and vice-versa.

Korsakienė, Stankevičienè, Šimelytė, \& Talačkienè, (2014) conducted study on the IT companies of Lithuania taking the response of 143 employees considering the retention and turnover issue. The main focus of this paper is to uncover the organizational and job related issues that push employees to leave the company. They have concluded that remuneration and challenging work are the crucial characteristics of the employment and suggested that participation in strategy development, remuneration and top management support explains the turnover of project manager whereas head of department turnover intention explained by working condition and career opportunities. Purohit, (2016) also conducted study to on information technology enabled service of India to sort out the causes of employee turnover and suggested the companies to give fair compensation, giving them more career advancement by promoting and reducing the dissatisfaction of employees by making collaborative environment between subordinate and managers so that it will reduce turnover and ultimately decrease the hidden cost. In the same line (Guha \& Chakrabarti, 2016) have also conducted exploratory study on IT employees to address the attraction and retention of employees as this is the prime concern of every potential organization. They have explored the impact of differential natural attitude of employees on their lives and work which ultimately leads to turnover intention. Using logistics regression model they have concluded that higher level of the salary attracts the young employees and in general the brand name of the company and big portfolio firms attract the employees which ultimately increase the turnover.

Kang, Huh, Cho, \& Auh, (2015) have conducted the study on the non-profit organization of North Korea as in the last decade in North Korea non-profit organization have experienced the high turnover. The main focus of the study is to find out the reasons that why the employees are shifting from non-profit organizations to profit earning organization and they have found out that age factor, remuneration, and size of the non-profit organization put impact on more than half of the employees to think of turnover and if we see specifically the job factors career advancement and job content are the main predictor of the job switching. Metin Camgoz, Tayfur Ekmekci, Bayhan Karapinar, \& Kumbul Guler, (2016) conducted study using work engagement as mediating variable between job insecurity and turnover intention using the sample of 309 respondents of Marmara city of Turkey. They have concluded that mediating role of work engagement is significant in case of losing privileges of job not in case of losing the job and it will further lead to turnover thinking. Moreover, the mediating role of the work engagement in case of losing privileges of job on turnover 
is stronger for women than men. Kossivi, Xu, \& Kalgora, (2016) stated that organization goal is to attract the talented people but at the same time to retaining them is also the challenge. In this regard they have taken multiple factors that impact the turnover including career advancement opportunities, remuneration, role of leadership, work place environment, training and development. After taking the vast number of turnover factors they have concluded that this area is not conclusive and it should further have investigated. Uptill now we have discussed the content and process of the turnover but (Rothausen, Henderson, Arnold, \& Malshe, 2017) have analyzed the phenomenon of turnover from 'Why' angle. They have added the new layer to understanding of the retention and turnover by conducting in-depth interview with leavers and stayers. They have used grounded theory method and found that the element of identity and well-being when perceived threat through different domains of life leads to diverse level of psychophysiological rinsing and in turn it leads to cope these thing by reassessment and it often lead to turnover. Contrary to this when there is good facilitation to well-being and identity it leads to retention of employees as it helps to cope the psychophysiological phenomenon successfully. Conclusively, we can say that in every type of organizations are facing the issue of turnover and turnover intention of every industry are mostly different each other but at the same time there are some common issue like career advancement and work life balance. We have taken model from (Hanqin Qui et al, 2014) about the antecedent of turnover of Chinese hotel employees and will try to expand it into two layers.

\section{Baseline Model: (figure-01)}

\section{Hanqin Qiu et al.}

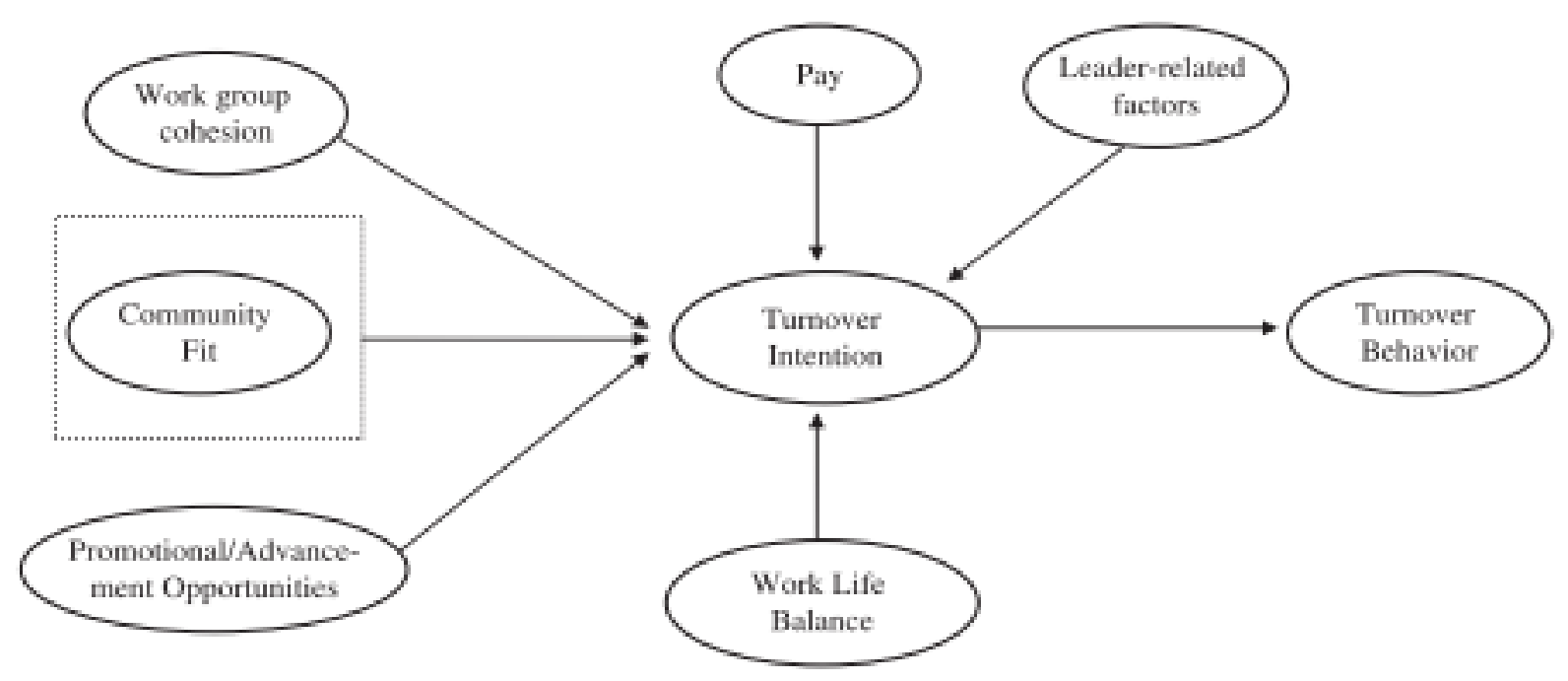

\section{Methodology and Data analysis:}

To have the better understanding of the turnover phenomenon of BPO industry of Pakistan and to enrich the literature of turnover, we have selected only one leading BPO of Pakistan on the basis of purposive sampling. Due to confidentiality matters in this study we didn't reveal the name of that organization and the reason for selecting only one organization is time constraint and access for data collection. we have collected the two-years data for reasons of leaving of employees of that organization. As per the procedure of the organization, whenever employee exit from the organization they have to give exit interview in which employee mention the reasons of leaving the organization and best part of this interview is that an employee is free to express his reason of leaving. The purpose of this interview is to maintain the record and it also mention in the offer letter, while any employee takes on board, that employee has to give the exit interview in case of voluntary but in case of involuntary turnover the reason on usually mention in the record by human resource department itself. As the reason for leaving were available in the raw form data and in total 678 employees reasons of leaving analyzed by using qualitative data analysis technique of content analysis. We have used the top down approach as we have two main themes that were voluntary and involuntary turnover and further 
categories and sub categories of these themes emerged with the help of data analysis. The process of doing the coding conducted and also cross checked by the independent HR representative to ensure its reliability. On the basis of content analysis, we have depicted the conceptual framework which shows the relationship between themes and categories then the relationship between categories and subcategories. Further explanation of the data is mention in the data analysis where we have explained each sub-category and show further analysis that with percentage of each category and theme into total turnover.

\subsection{Data Analysis:}

From two main themes of turnover, three categories emerged from the data analysis, for voluntary turnover only one category namely resignation is revealed and for involuntary turnover two categories called termination and separation revealed. After that we have further analyzed and revealed sub-categories. In case of involuntary turnover, for separation there is only one subcategory found in the data called cost cutting and for termination we have six main sub categories and these are insubordination, malpractice, poor performance, violation of company policy and procedure, negative behavior and last is no call no show. Coming toward the voluntary turnover, we have come up with nine main reasons career advancement, could not manage his studies \& work, grievance with the management, medical issues, moving to new city, personal issues, remuneration, study completion and finally the work life balance.

$\underline{\text { Table:01 Coding of data }}$

\begin{tabular}{|l|l|l|l|}
\hline Themes & Categories & Subcategories & $\begin{array}{l}\text { Count of Reason for } \\
\text { Leaving }\end{array}$ \\
\hline Involuntary & Separation & Cost Cutting & 12 \\
\hline & Separation Total & & $\mathbf{1 2}$ \\
\hline & Termination & Insubordination & 5 \\
\hline & & Malpractice & 11 \\
\hline & & Poor Performance & 50 \\
\hline & & Violating Company Policies \& Procedures & 11 \\
\hline & & Negative Behavior & 5 \\
\hline & & No Call No Show & 118 \\
\hline & & & $\mathbf{2 0 0}$ \\
\hline & Termination Total & Career Advancement & 200 \\
\hline & & Could Not Manage His Studies \& Work & 23 \\
\hline & & Grievance With The Management & 8 \\
\hline & Medical Issues & 28 \\
\hline & & Moving To New City & 53 \\
\hline & & Personal Issues & 103 \\
\hline & & Remuneration & 3 \\
\hline & & Study Completion & 38 \\
\hline & & Work Life Balance & 10 \\
\hline & & & $\mathbf{4 6 6}$ \\
\hline & & & $\mathbf{6 7 8}$ \\
\hline
\end{tabular}

This information is also presented in the above table- 01 where we can see the subcategories under categories and categories under themes further we have also mention the count of each sub category. Below in table-02 we have described the percentage of each category with respect to total turnover percentage of past two years. The interesting result we have seen that in case of involuntary turnover where $1.8 \%$ of total leaver employees due to the cost cutting reason under the separation category and in termination category $29.2 \%$ of employees ceased to work due to six reasons as mentioned above but in case of voluntary turnover we have only one subcategory which is resignation and it contain $69 \%$ of total turnover and it has main portion in total turnover ratio. 
Table:02 Percentage of each category:

\begin{tabular}{|l|l|}
\hline Categories & \%age of each category in total turnover \\
\hline SEPARATION \%age & $1.8 \%$ \\
\hline TERMINATION \%age & $29.2 \%$ \\
\hline RESIGNATION \%age & $69 \%$ \\
\hline
\end{tabular}

Below in table-03, we have aggregated the all reasons of turnover whether it is from voluntary and involuntary then derived the percentage of each subcategory. The most dominant subcategory is the 'career advancement' which shows $29.5 \%$ of total turnover and this high attrition percentage result is in line with (Sivarethinamohan \& Aranganathan, 2013); (Bharathi \& Paramashivaiah, 2015) who stated that the main reasons for high attrition in BPO industry is the low career growth as the experience of BPO is not acceptable in the market as other organization experience. Secondly, most dominant subcategory is 'no call no show' which means employee left the organization without any intimation and didn't come back to work.

\section{Table:03 Percentage of each Reason:}

\begin{tabular}{|l|l|}
\hline \%age of each subcategory in total turnover & $1.77 \%$ \\
\hline Cost Cutting & $\mathbf{0 . 7 4 \%}$ \\
\hline Insubordination & $1.62 \%$ \\
\hline Malpractice & $\mathbf{7 . 3 7 \%}$ \\
\hline Poor Performance & $\mathbf{1 . 6 2 \%}$ \\
\hline Violating Company Policies \& Procedures & $\mathbf{0 . 7 4 \%}$ \\
\hline Negative behavior & $\mathbf{1 7 . 4 0 \%}$ \\
\hline No call No Show & $\mathbf{2 9 . 5 0 \%}$ \\
\hline Career Advancement & $\mathbf{3 . 3 9 \%}$ \\
\hline Could not manage his studies \& work & $\mathbf{1 . 1 8 \%}$ \\
\hline Grievance with the management & $\mathbf{4 . 1 3 \%}$ \\
\hline Medical Issues & $\mathbf{7 . 8 2 \%}$ \\
\hline Moving to new city & $\mathbf{1 5 . 1 9 \%}$ \\
\hline Personal Issues & $\mathbf{0 . 4 4 \%}$ \\
\hline Remuneration & $\mathbf{5 . 6 0 \%}$ \\
\hline Study Completion & $\mathbf{1 . 4 7 \%}$ \\
\hline Work life balance & \\
\hline
\end{tabular}

The former subcategory is of voluntary theme and later on is of involuntary turnover. Apart from these significant subcategories another subcategory under the voluntary turnover is 'personal issue' it has $15.19 \%$ of total turnover and it has also significant ratio and third highest ratio among other subcategories. Apart from these most significant subcategories study completion, poor performance, moving to new city and medical issue also has more than 4\% -8\% of total turnover. So conclusively we can say that in case of voluntary turnover, career advancement and personal issue are the main subcategories and incase of involuntary turnover 'no call no show' and poor performance. Further we have depicted the percentage of these each subcategory with the help of graph (figure-02) using the pie graph and most dominant subcategories that we have discussed are prominent in the it.

The following section will explain the each of these four main subcategories and will also show the actual wording of the employees what they have mentioned in the exit interview and incase of involuntary turnover the reason that organization have mention will be discussed. 


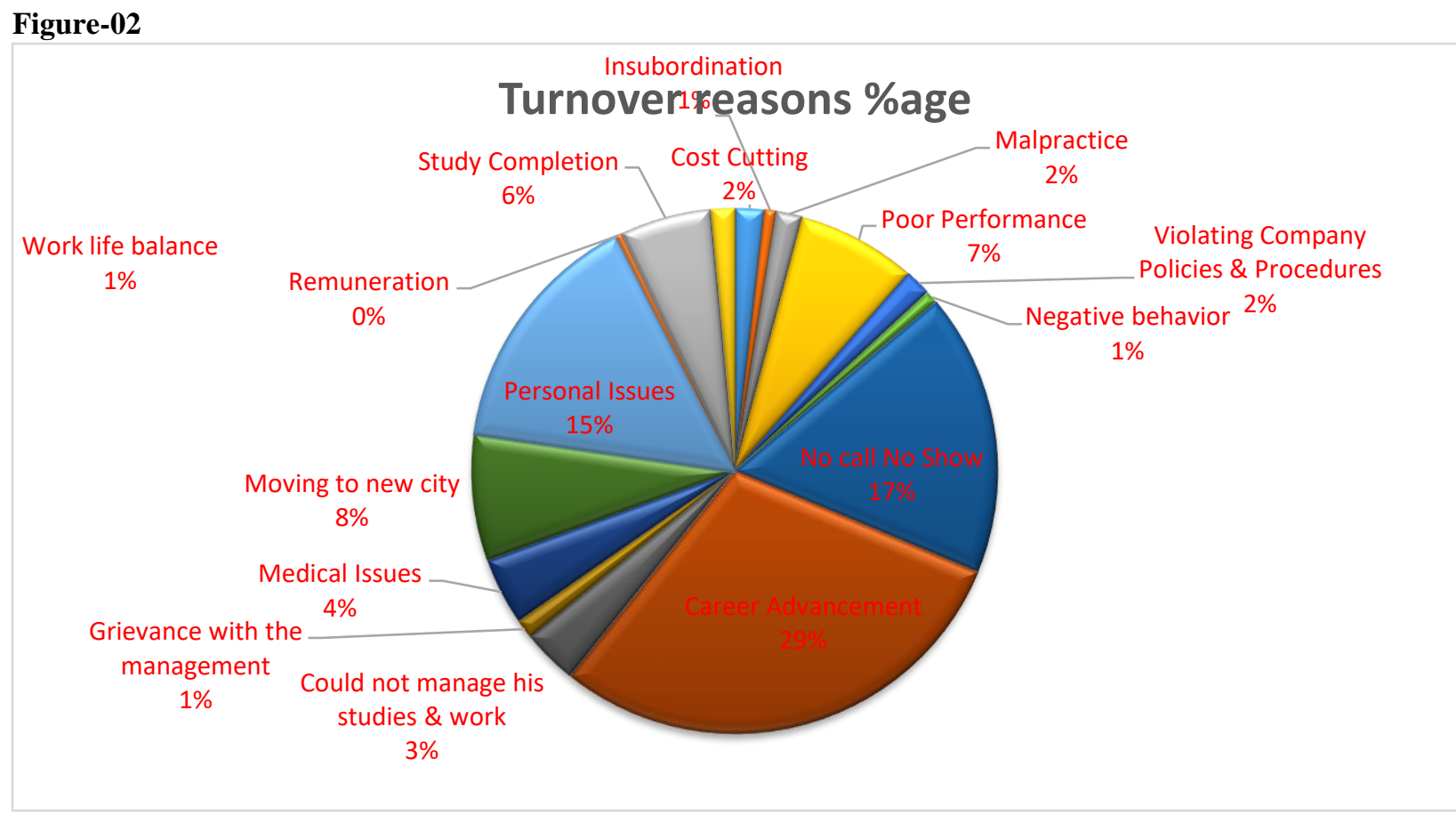

\section{Discussion:}

\section{- Career advancement:}

Out of $100 \%$ employee who left the organization, $29.5 \%$ of them have stated that career advancement as an important factor while making decision of quitting. One of the employee stated that;

"Employee resigned as he thinks that he has not been given any growth opportunities whereas his Assistant manager offered for him to be SWAT player to which he declined"

But this is the statement of only one employee who left but at the same time if we observe the percentage of switching for career advancement as whole, we came to know that, in the same industry, 36.5\% of employees moved for career advancement while remaining employees joined other industries. So we can say from this ratio most of the employee who use to leave the BPO industry mostly change their industry. And also it is implicit from the sky high percentage that there is less career advancement in that organization. And If we see this scenario from Maslow's hierarchy theory of Need (1943) lens, when the basic needs get satisfied employee goes to think about self-actualization which include realization of goals, high hopes and dreams. For that most of the employee move.

\section{- Personal issues:}

This is the second highest factor of voluntary turnover as it has $15.19 \%$ of total turnover ratio. Most of the employees have said that the have some family issues as one of the employee stated while in exit interview;

"Employee's father is ill and he has to look after his father"

"Employee resigned due to family commitments"

And apart from the above said reasons just said that they have 'personal issues' and didn't mention anything else. If we see this subcategory from the 'work life balance angle' it is the perfect synonym of it. According to (Karatepe \& Kilic, 2007), if there is conflict between responsibilities of family and work life then it is probable that it leads to employee turnover. However, they have said this statement on the basis of hotel industry but this scenario perfectly applies on the BPO industry as this industry working hour is night shift and main employees has to work for longer hour and inflexible roster which lead to affect the work life balance. 
The above two subcategories belong to voluntary turnover theme and in our study this theme has only one main category called 'resign'. The next two sub-categories will be of involuntary turnover. The reason for mentioning is to remind that, in case of voluntary turnover, employees mention the reason of leaving whereas in case of involuntary turnover human resource department mention the reason in the record. However involuntary turnover has less ratio if we compare it with the voluntary turnover ratio.

\section{- No call no show:}

This subcategory belongs to involuntary turnover, it means if an employee leaves the organization without any notice and didn't appear. This is basically the policy of the organization if any employee who leave the organization without any prior notice and doesn't appear then human resource department updated the status of employee as 'leaver' in Human Resource Management System' and mention reason as 'No call no show'. If we see in the turnover literature this term won't be seen as other reasons but in BPO industry of Pakistan this issue prevails. As it has the significant percentage in whole turnover ratio that's why we cannot ignore this subcategory of termination. The reason that I have found in data are;

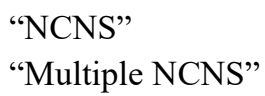

The multiple NCNS means an employee who do this act more than one time then human resource department terminate these type of employees but multiple NCNS are only $10 \%$ of this subcategory and only $2 \%$ of whole turnover ratio.

\section{- Poor performance:}

This subcategory is also belonging to involuntary turnover under the category of termination. There are multiple reasons of poor performance and some of the reason are;

"Poor Performance \& Tardiness Issues"

"Poor Performance \& Lack of focus towards work."

"Poor Quality, Tardiness \& inability to get certified by the client"

"Employee was Terminated as a result of low performance"

"Quality Issues"

Mainly these are the five reasons which severely impact the performance of the employee and if any of these will occur with abnormal frequency it will lead to termination of an employees.

\section{Proposed framework and implications:}

Based on the above mentioned results, we have proposed a comprehensive framework of turnover intention in (figure3). Cost Cutting, Insubordination, Malpractice, Poor Performance, Violating Company Policies \& Procedures, Negative behavior, no call no Show, Career Advancement, could not manage his studies \& work, Grievance with the management, Medical Issues, Moving to new city, Personal Issues, Remuneration, Study Completion, Work life balance. This comprehensive framework has added to an existing theoretical framework of the (Hanqin Qui et al, 2014) as shown in (figure-01). If we see existing framework the have just showed up the turnover intention around the turnover in hotel industry of the China, but in this study we have extended in two layer called categories of turnover and then subcategory of each category. Additionally, this study is based on the BPO industry of Pakistan so it has far different dynamics than hotel industry but at the same time some of the turnover intentions matched. This study confirms the framework of (hanqin qui et al 2014) that career advancement and work life balance (in our study personal issues) are crucial factor of turnover intention. Ito \& Brotheridge, (2005) stated that if there is supervisory career support for enhancement of employee adaptability it will increase the employee commitment and decreases the turnover intention. This study implies that if there is adequate training and career plan development within the organization then there will be less turnover due to career advancement. Secondly, work life balance (in our study personal issues) is very important factor, as (Gupta, 2013) stated that the main reason for high turnover in BPO industry is the odd timing of office as night shift is completely contradicting with the usual life and it disturbs the work life balance but this ratio can be decrease if we made the flexible hours for the employees at the time of family commitment and accommodate the employees in hour of need. For involuntary turnover, poor performance can be decrease if at the time of hiring an employee go through strict criteria for hiring so that potential employees only get hire and screen out the less potential candidates. 


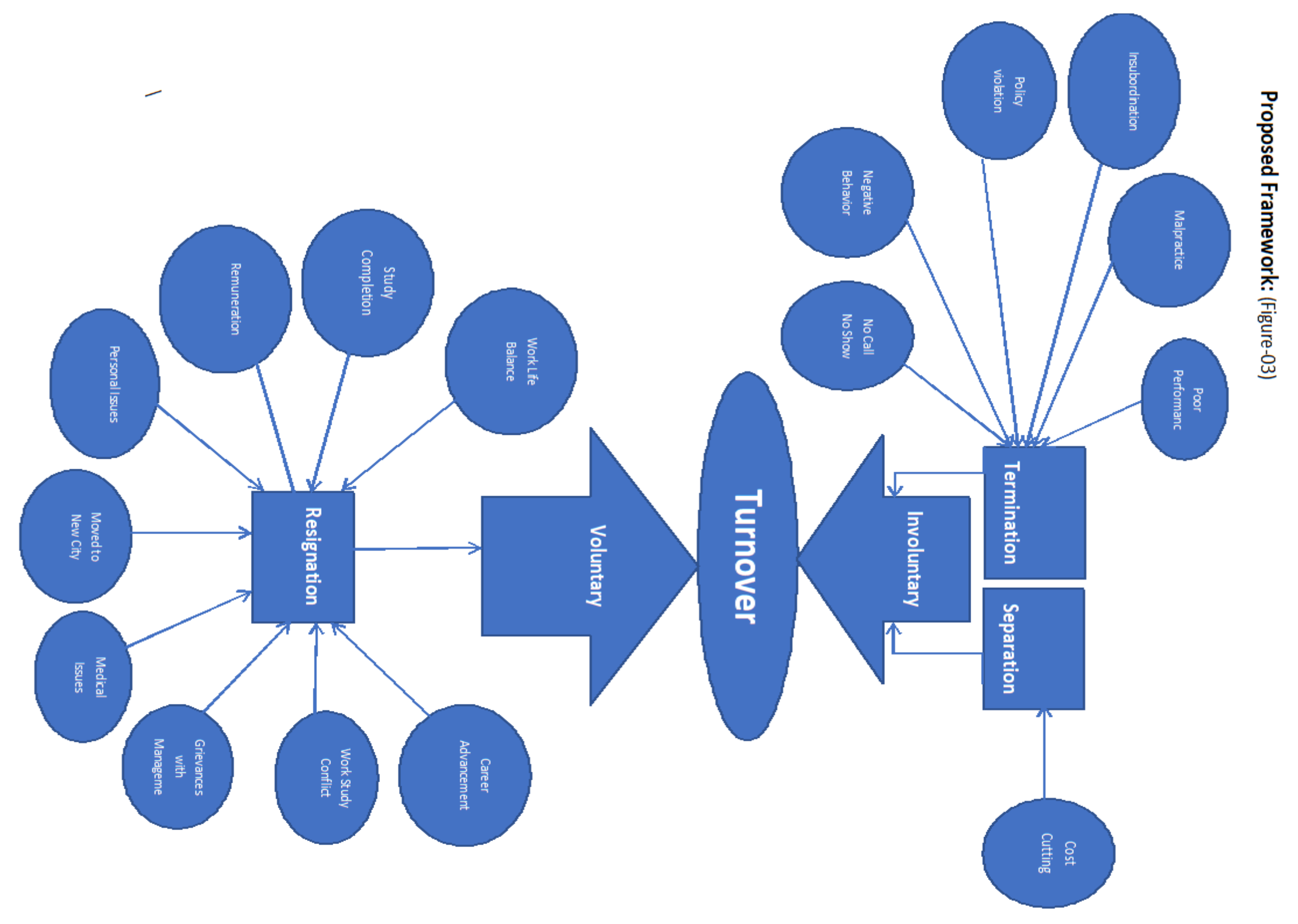




\section{Conclusion:}

This study explores the determinants of employee's turnover intention of the BPO industry of Pakistan taking sample of one of leading BPO situated in Pakistan. Based on the results that we have explored in our study, there are various factors that leads to turnover. Some of the determinants that we have explored, are common in turnover intention literature but some are new like "no call no show" which means if an employee leaves the organization without any notice and didn't appear. Over all the antecedents of turnover that we have found are Cost Cutting, Insubordination, Malpractice, Poor Performance, Violating Company Policies \& Procedures, Negative behavior, no call no Show, Career Advancement, could not manage his studies \& work, Grievance with the management, Medical Issues, Moving to new city, Personal Issues, Remuneration, Study Completion, Work life balance.

This study enhanced the existing theoretical framework of the Hanqin Qui et al (2014). If we see their framework the have just showed up the turnover intention around the turnover in hotel industry of the China, but in this study we have extended in two layers called categories of turnover and then subcategory of each category. But at the same time this study has some limitations. Data of turnover intention is of one BPO situated in Pakistan thus we cannot generalize the result of this study at all BPO industry employees. Future research can be done taking the data more than one BPO organization and conducting interviews of employees.

\section{References:}

Alam, S. M. T. (2015). Factors affecting job satisfaction, motivation and turnover rate of medical promotion officer (MPO) in pharmaceutical industry: a study based in Khulna city. Asian Business Review, 1(2), 126-131.

Aranganathan P and R. Sivarethinamohan (2012), "Quality of work life as perceived by employees in private sectormanufacturing companies”, Elixir Human Resource Management, 44 (2012)Pp. 7462-7470.

Bharathi N. \& Paramashivaiah P. (2015)Attrition and Retention the Real Challenge-aStudy with Special Reference to IT and ITES Organizations in Bangalore International Journal of Innovative Research in Science, Engineering and Technology Vol. 4, Issue 2, February 2015 Pp 746-52

Brown, E. A., Thomas, N. J., \& Bosselman, R. H. (2015). Are they leaving or staying: A qualitative analysis of turnover issues for Generation Y hospitality employees with a hospitality education. International Journal of Hospitality Management, 46, 130-137. https://doi.org/10.1016/j.ijhm.2015.01.011

Brown, E. A., Thomas, N. J., \& Bosselman, R. H. (2015). Are they leaving or staying: A qualitative analysis of turnover issues for Generation Y hospitality employees with a hospitality education. International Journal of Hospitality Management, 46, 130-137.

Camgoz, S. M., Ekmekci, O. T., Karapinar, P. B., \& Guler, B. K. (2016). Job insecurity and turnover intentions: Gender differences and the mediating role of work engagement. Sex Roles, 75(11-12), 583-598.

Chakrabarti, S., \& Guha, S. (2016). Differentials in Information Technology Professional Category and Turnover Propensity: A Study. Global Business Review, 17(1), 90S-106S. https://doi.org/10.1177/0972150916631086

Chaturvedi, A., \& Sangwan, K. (2016). Impact of Job Satisfaction on Retention of Employees in BPO Industry. Ssrn, 5(11). https://doi.org/10.2139/ssrn.2803029

Dess, G.G. \& Shaw, J.D. (2001) Voluntary turnover, social capital, and organizational performance. Academy of Management Review, 26, pp. 446-456.

Feng, H., \& Cao, M. (2017). The individual influence factors of voluntary turnover among knowledge workers in China: A case study of Huawei. Journal of Contemporary Eastern Asia, 16(2).

Guha, S., \& Chakrabarti, S. (2016). Differentials in attitude and employee turnover propensity: A study of information technology professionals. Global Business and Management Research, 8(1), 1. 
Gupta, V. (2013). An analysis of attrition: retention strategy for IT/BPO industry. International Journal of Advance Research in Computer Science and Management Studies, 1(7).

Hayward, D., Bungay, V., Wolff, A. C., \& MacDonald, V. (2016). A qualitative study of experienced nurses' voluntary turnover: learning from their perspectives. Journal of clinical nursing, 25(9-10), 1336-1345.

Ito, J.K., \& Brotheridge, C.M. (2005). Does supporting employees ' career adaptability lead to commitment, turnover, or both? Human Resource Management, 44(1), 5 - 19.

Kang, C., Huh, S., Cho, S., \& Auh, E. Y. (2015). Turnover and Retention in Nonprofit Employment: The Korean College Graduates' Experience. Nonprofit and Voluntary Sector Quarterly, 44(4), 641-664. https://doi.org/10.1177/0899764014553032

Karatepe, O.M., \& Kilic, H. (2007). Relationships of supervisor support and conflicts in the work-family interface with the selected job outcomes of frontline employees. Tourism Management, 28(1), $238-252$.

Korsakienė, R., Stankevičienè, A., Šimelyte, A., \& Talačkienė, M. (2014). Factors Driving Turnover and Retention of Information Technology Professionals. Journal of Business Economics and Management, 16(1), 1-17. https://doi.org/10.3846/16111699.2015.984492

Kossivi, B., Xu, M., \& Kalgora, B. (2016). Study on Determining Factors of Employee Retention. Open Journal of Social Sciences, 04(05), 261-268. https://doi.org/10.4236/jss.2016.45029

Li, J., Xu, W. W., Wang, F., Chen, S., \& Sun, J. (2018). Examining China's Internet Policies through a Bibliometric Approach. Journal of Contemporary Eastern Asia, 17(2), 237-253. https://doi.org/10.17477/jcea.2017.16.2.003

Malhotra, A., \& Gautam, A. (2016). Factors Leading to Employee Attrition in BPO Industry: A Review of Literature in the Indian Context. International Journal in Management \& Social Science, 4(10), 163-168.

MALHOTRA, A., \& GAUTAM, A. (2016). HRM PRACTICES AND EMPLOYEE ATTRITION: A GENDER CENTRIC ANALYSIS OF INDIAN BPO INDUSTRY. CLEAR International Journal of Research in Commerce \& Management, 7(11).

Malik, O. F., Sattar, A., Shahzad, A., \& Faiz, R. (2017). Personal Bullying and Nurses' Turnover Intentions in Pakistan: A Mixed Methods Study. Journal of Interpersonal Violence, 1-21. https://doi.org/10.1177/0886260517719903

Maslow, A.H. (1943). A theory of human motivation. Psychological Review, 50, 370 - 396

Metin Camgoz, S., Tayfur Ekmekci, O., Bayhan Karapinar, P., \& Kumbul Guler, B. (2016). Job Insecurity and Turnover Intentions: Gender Differences and the Mediating Role of Work Engagement. Sex Roles, 75(11-12), 583-598. https://doi.org/10.1007/s11199-016-0595-0

Pereira, V., Malik, A., \& Sharma, K. (2016). Colliding Employer-Employee Perspectives of Employee Turnover: Evidence from a Born-Global Industry. Thunderbird International Business Review, 58(6), 601-615.

Purohit, M. (2016). A Study on - Employee Turnover in IT Sector with Special Emphasis on Wipro and Infosys. Journal of Business and Management, 18(4), 2319-7668. https://doi.org/10.9790/487X-1804014751

Qiu, H., Haobin Ye, B., Hung, K., \& York, Q. Y. (2015). Exploring Antecedents of Employee Turnover Intention Evidence of China's Hotel Industry. Journal of China Tourism Research, 11(1), 53-66. https://doi.org/10.1080/19388160.2014.908756

Rahman, K. (2017). Analyzing the Factors Influencing Employee Turnover in Private Commercial Banks in Bangladesh. Ssrn. https://doi.org/10.2139/ssrn.2952201

Rothausen, T. J., Henderson, K. E., Arnold, J. K., \& Malshe, A. (2017). Should I Stay or Should I Go? Identity and Well-Being in Sensemaking About Retention and Turnover. Journal of Management, 43(7), 2357-2385. https://doi.org/10.1177/0149206315569312 
Shah, Hardik\& Sharma Vinay (2007) "Can Job Satisfaction Enhances Individual Performance: Empirical Study From BPO Sector"Global Journal of Business ManagementVol. 1 No. 1, June 2007 P 55-67

Sivarethinamohan, R., \& Aranganathan, P. (2013). Employee attrition: Exploring the dimensions in the Urban Centric Indian BPO industry. JIMS8M: The Journal of Indian Management \& Strategy, 18(4), 4-12.

Tamilzharasi, K., \& Uma, Rani. (2014). "A Study on work stress and job performance evaluation of BPO employees." International Journal of Advanced Research in Computer and Communication Engineering 3(1), 5093-510 